\title{
CHALLENGES AND SCOPE IN LOGISTICS SERVICES - A COMPREHENSIVE STUDY IN INDIAN CONTEXT
}

\author{
Yashraj Rautia ${ }^{1}$, Dr. Prashant Barge ${ }^{2}$ \\ ${ }^{1}$ Symbiosis Institute of Operation Management, Symbiosis International (Deemed University), Pune, India
}

\begin{abstract}
The logistics sector in India contributes to 14\% in GDP and recently has added a lot of consideration from both business industries as well as policy makers. Fluctuating government policies on tax system and guidelines of service providers are going to play an important role in logistics industry. Coordination among many government agencies needs agreement from various ministries and is a barrier for multi modal transportation in India. Growing demands from e-commerce industry and Government initiatives like MAKE IN INDIA, will absolutely bring considerable development for logistics service providers in India. The LSPs need to restructure their strategies with the purpose of gaining all approaching opportunities. LSP's in India are facing many challenges with the intention to deliver shipments on assured time and in proper condition. In this study, it has been attempted to highlight the challenges faced by LSP's and what measures can be taken to mitigate the challenges. Based on the opinions of experts and literature reviews from few journals, the challenges and solutions has been identified. This study explains how globalization plays an important role in driving the Indian logistics industry and detailed information about each challenge.
\end{abstract}

\section{Keywords:}

Contribution to GDP, Logistics service providers, Globalization, Challenges.

Article Received: 10 August 2020, Revised: 25 October 2020, Accepted: 18 November 2020

\section{Introduction}

In the term supply chain management (SCM), logistics plays a very important role. logistics is nothing but the management of the flow of goods from one location to another. Logistics can likewise be characterized as the management of all the exercises which include planning, execution, charge over the shipment of products, and data sharing between the sender and the recipient. While in SCM, logistics is the term allocated to the management of the supply of the goods by the use of various mode of transportation like road, air, sea, rail or multimodal medium. Some logistics companies have their own fleets or they hire third-party logistics providers (3PL) which take control over the movement of goods. Logistics is nothing but the activity which involves movement of resources from one place to another consuming right cost and time by delivering it in right quantity at right place and at the right time.

The Logistics sector in India is increasing its importance in the role of the Indian economy as it contributes to $14 \%$ of India's GDP. Logistics performance index has ranked India currently on 44th position among a total of 160 countries around the world. The emerging demand from the e-commerce and manufacturing sectors are forcing logistics sectors to make changes in their strategies in order to provide better services to their customers. The logistics sector in India has affected gravely by Covid-19 in the nation but it is also expected that the logistics sector would grow much faster after the Covid-19 pandemic ends. The emerging demand from the e-commerce and manufacturing sectors are forcing logistics sectors to make changes in their strategies in order to provide better services to their customers.

LSP's in India have an abundant opportunity to grow and enlarge their business due to emerging demands and also from the latest initiative of "MAKE IN INDIA" taken by Indian Government. In India, as much as three-fifths of transport happens through roadways, so it becomes very important for logistics companies to focus on the challenges faced in transportation (Kumar et al., 2012). There are some challenges related to Infrastructure, absence of integration amongst stakeholders, lack of talented manpower and moderate appropriation of innovation and technology keep on burdening the pressure on logistics companies. These barriers sometimes become an important cause behind why the LSP's fail to provide the desired services. The objective of this research is to make sure that, what Indian 
LSP's should implement to fulfil customer demands, for that purpose the challenges need to be observed, identified and terminated by taking necessary actions.

\section{LITERATURE REVIEW}

As per Christopher (2016), Logistics is said to have risen up out of the military as the control showed up from the need of a precise and adequate supply of the water, clinical assets, ammo, food, and fuel to the soldiers and was presented in the military throughout second world war. These days, Logistics can be characterized as the management of all the exercises associated with the progression of goods including planning of activities, execution, command over the flow and storage of the items and movement of data between the sender and the end receiver. The logistics can be simply defined as the goods should be present at right place, at right time, at right quantity, and at right cost. Throughout the long term, markets have changed because of intense rivalry that emerged from globalization. All these new improvements have driven the Logistics organizations to search for more productive procedures to offer better support.

Tezuka k (2011) depicts the most required properties of service organizations as an interconnected, contract, and also consulting. The notoriety of outsourcing logistics emerges for various reasons. For the most part, Indian associations outsources 3PL providers to diminish their cost engaged with entire logistics activity, they centre more around centre abilities, better quality of service, and efficient. As of now, transportation is viewed as the most pivotal logistics activity which nearly represents $50-60 \%$ followed by warehousing which represents 25 $30 \%$ of the whole market, which is additionally trailed by value added activities and fright management responsible for the remaining market. The organizations consistently make an endeavour for improving the nature of their services with the goal of more fulfilled clients. The improvement in the nature of service causes organizations to lessen cost just as to expand benefits simultaneously.

There is a need to recognize and examine the challenges looked by LSP's in providing the ideal quality to the end clients. In light of the expert's opinion, various challenges looked by LSP's are distinguished as Complex State Documentation,
Lack of coordination with clients are viewed as significant yet after introduction of Goods and Service Tax (GST) in India, these obstructions have consequently disappeared to a huge degree. Most of the goods in India, transports through roads, as compared to other transport modes. Based on CILT report Figure explains the amount of goods transported through roads.

In India the total percentage of goods transport by means of road ranks highest as compared to other top developed countries like China, USA. Hence, there is a possibility that the foreign players would try to capture the Indian markets as there is huge scope for them. Considering this issue Indian logistics service providers needs to stay updated with latest technologies and strategies to compete in this competitive industry.

\section{Globalization and its impact on India logistics services}

(Andrzej Szymonik 2014) explains Globalization is the process of the integration of the different countries which generally happens through greater foreign trade and foreign investments. It has great impact on Indian economy. The globalization in Indian Industry has beneficial effects on many industries which happened due to huge amount of foreign investments in Pharmaceutical, Petroleum, BPO and majorly in manufacturing industries. It has boosted the Indian economy significantly by means of huge amount of Foreign direct investments (FDI).

These boost in the industries due to globalization, the demand for logistics has increased more because various multinational national companies (MNS) are manufacturing and supplying the material on an international level.

Due to globalization, the demand for fast-moving consumer goods (FMCG) and electronic items in India has been developing at a quick rate. A few MNCs from various industries have shown a developing enthusiasm for setting up elite manufacturing industries in India to take into account the domestic market and export market. The Indian automotive industry is headed to getting one of the world's significant vehicle manufacturing centre points. Creating manufacturing facilities in India has been a vital move to diminish their manufacturing expenses and oblige the growing Indian market. Indian markets have seen tremendous growth since the opening of automotive industries. 


\section{Challenges faced by logistics service providers in India}

(S. Sowjanya, 2017) clarifies regardless of many best practices followed by the LSP's in India, the LSP's still face challenges in some point. Indian subcontinent faces different challenges as compared to other developed nations. In other nations generally the problem faced by LSP's is demand, on the other hand in India, demand is high but the management of those demands has been a great challenge for LSP's. India is still struggling in terms of best practices.

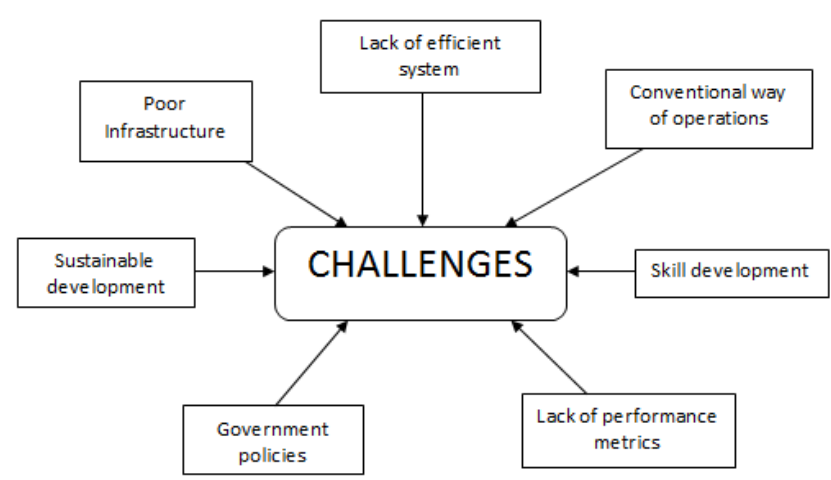

Figure 1: Challenges faced by Logistics Service Providers

\section{Poor Infrastructure / Transport Related Challenges}

(Venkatesh et al., 2017) Infrastructure is one of the greatest challenges which has limited the development of Indian logistics sector. The challenges occur due to pathetic condition of the roads, which leads to reduce the average speed of the vehicle, and low daily average distance covered by the vehicle, it enhances the wear and tear of the vehicle (Sahay et al.,2006). It results in the high maintenance and reduces the performance of the vehicles. Hence, the vehicle takes much more time to reach its destination and also consumes more fuel during transit, all these issues leads increase in the cost of transportation. As mentioned before, movement through roads are the predominant mode of transportations of freight cargo, which is nearly to the $60 \%$ of the total mode of transportation. While the $31 \%$ of goods are moved by the mode of railways, $8 \%$ of freights are moved by sea/water mode and the remaining $1 \%$ is transported by means of air mode of transport (JLL Report).

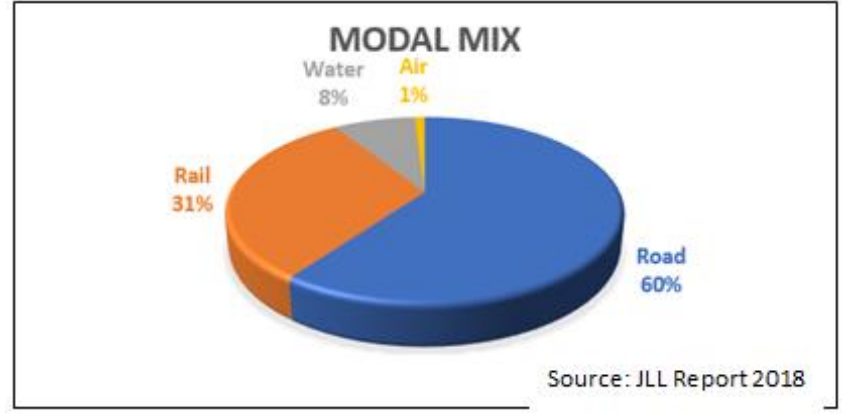

Figure 2: Total Freight transport modal mix

\section{Lack of Efficient Technical System}

Use of latest technologies in day by day activities has been another large limitation. Understanding among the representatives about the economic advantages of using advanced technology is exceptionally less and cooperation among partners a long way from the ideal prerequisite (Luisa et al., 2013). Subsequently, the logistics environment is stressed over operational shortcomings and moderate resource usage. The missing advanced technology systems and inadequate technical information among laborers add to the agony. Innovative foundation has stayed deficient, set apart by moderate system speeds, unsuitable performance, and erratic equipment and programming these all lead to significant expense and underperformance (Sauvage, 2003).

The logistics business is influenced by low paces of innovation usage and less skills ability levels (Rohita Mishra, 2004). Automation in measures is still just in its beginning phase. Further advancement depends on a specific degree of standardization which has gotten more troublesome by the fragmentation in the business. On the technology contemplations, the business currently is by all accounts giving genuine consideration to the utilization of Warehouse management system, Radio Frequency Identification (RFID), device for vehicle tracking, and so forth. Maybe, accepting isn't an obstacle any longer, the cooperation among IT and business requirements should be settled (Luisa et al., 2013). This downside should be handled first. Notwithstanding technology related issues, the expertise levels of this business additionally need to be overhauled as quickly as time permits.

\section{Traditional Ways of Operations}

In India, one of the most significant bottlenecks upsetting the LSP's is the out dated way in which things are running their operations. Activities like inspection, paper work, material handling 
equipment's, use of improper way of handling material, usage of out dated technologies etc, brings inefficiency in the operations and it also consumes time (Sharma et al., 2011). No integration between the clients leads to involvement of middleman which charges money for their service and subsequently prompts an expansion in non-required general activity costs

With a different customer base, the customers desire and practices are likewise varied. There is a requirement for transparency, standardization of processes, straightforwardness, and consistency with the customers. In this manner, LSP's have to adjust their thoughts and methodology to the standard plan of action to their focused-on client base. The request from the different clients request to provide customization in the services, adaptability, fast services. Because of these difficulties and the predominance of different suppliers, there is a prerequisite for the cooperation by integrating the services so as to accomplish the needs (Mitra, 2006). Also, activities, for example, continuous tracking material and visibility value added services would enable the logistics to reduce undesirable expense, raise their profitability and effectiveness in the supply chain.

\section{Lack of appropriate performance metrics}

(Rajesh et al., 2011) In the logistics area, Key performance index plays a very significant role for calculating costs, and quality rates. Likewise, the information acquired by these KPI's would straightforwardly affect the management of the company's logistics services, as they permit you to persistently keep track on all the metrics identified within the supply chain. Absence of the performance metrics leads to inappropriate operations and results in high consumption of time as well as cost.

\section{Skill Development / Shortages of Skilled Workforce}

India has a segment advantage over different nations yet the accessibility to skilled labour stays a test. The lack of skilled labour is the aftereffect of deficient training and backing in the field of logistics operations (Govindan et al., 2014). The logistics business is especially considered as a support industry. The division needs to explicitly assemble a pool of work force which includes distribution centre administrators, truck drivers, quality review supervisors etc.
The LSP's in India still struggles to run in an organized manner, as this industry is completely based on manpower, and due to lack of institutional training support, it has resulted in insufficiency in management of customer service activities and shortage of skilled labour. Skilled manpower in 3PL services is still missing and implementation of training facility is much less than required (Govindan et al., 2014). There are very few training facilities for technical, operational and soft skills and due to disorganized manner of logistics, that further leads to inappropriate working environment and results in low wages to the workers, hence there is high attrition rate in this industry.

(Thai et al. 2011) explains why the Indian logistics industry is still struggling to get professional graduates as this sector does not lie in the choice of preference among young graduates. Hence, it is getting more difficult to onboard skilled employees in the organization. Individual with knowledge in safe operations, good understanding about the logistics industry, professional truck drivers and also holds technology skills as well as capability to handle multiple operations are considered as skilled employees in logistics operations.

\section{Lack of Government Support Policies Regulatory hurdles}

Government support for the desired policy, improvement, and identification is still lacking in this industry. The introduction of Goods and Service Tax from the Indian government could affect the operations in logistics at a great level only if it is properly executed. Different organizations, if not synchronized and conveyed under a solitary umbrella, could hinder the development and activity of Logistics framework. Absence of transparency in consistence further adds to the trouble of this industry.

(Vinod Kumar, Luthra et al., 2011) A complex tax system in a logistics industry leads to inappropriate method of payment and it results in

1. Increase in transit time of vehicles which caused due to waiting, while paying taxes.

2. Difficulties in allotment of low margin products in the warehouse hence, giving an obstruction to make a huge warehousing space for other products.

\section{Sustainable development}

(Sachin Kumar Mangla, 2020) Very few Logistics service providers in India shows concern with 
respect to the sustainability also utilizing pallets with reusable and recyclable material, and implementation of green processes as well as green vehicles in their daily operations. There are multiple reasons why logistics industries in India still lagging in sustainable development. (Abbasi and Nilsson, 2016) The reason can be less awareness about sustainability in the organization, no common set of rules for sourcing sustainably into the organization, fewer government policies focusing on Sustainability, etc.

\section{Solution to some of these challenges}

\section{Future Government Investments in Indian Logistics sector}

According to the Union Minister of Commerce \& Industry, the Government of India is expected to invest an amount of USD 5 trillion by 2025 (Atmanirbhar Bharat) into logistics sectors including infrastructure. This step by the government will provide employment to the millions and further reduce the difficulties occurring in internal and global trade business. As India is considered as a developing country, many foreign production and manufacturing companies are targeting Indian market as their service location. To address the challenges faced by logistics sector, the government has decided to take following steps

\section{Efficient and Multi-modal Transport Infrastructure:}

Promoting Intermodal Transport by focusing on developing transport infrastructure and multimodal logistics facilities for seamless and cost-effective multimodal transportation, encouraging operators to adopt multimodal operations, promoting containerization of cargo/other innovative solutions like RoRo service to enhance interoperability, developing guidelines to promote transparency in freight charges to encourage competition across modes.

\section{Improving Trucking and Road Transport}

A Unified Logistics Interface Platform (ULIP) would be developed, to function as a freight exchange portal, integrating GST e-way bills, VAHAN database, transit information on FASTag and leverage GPS / ELD system to map the flow of freight across the country to plan for infrastructure and improve operational efficiency; ULIP would include driver log tool, ULIP system would include driver log tool, to monitor time spent on wheels; incentivize and improve on-road amenities, thus creating an enabling transport environment for truck drivers, digital trucking application would be developed to track and evaluate performance of trucking companies to facilitate accreditation that are allowed unhindered movement across country (green channel).

\section{Attracting Freight for Indian Railways by focusing on}

Developing customized offerings catering to unique commodity requirements, promoting parcel business via scheduled time-table services, incentivizing service providers and users to shift to rail mode, creating a customer-oriented organization focused on service delivery, by promoting innovation in design of rolling stock to reduce turnaround time for loading/ unloading, deploy extra-long freight trains on dedicated corridors with increased speed and electrified double-decker freight trains, equipped with horizontal loading/unloading to enhance operational efficiency.

\section{Promoting Coastal Shipping}

Increase modal share of coastal shipping through developing dedicated berths for coastal cargo, bunkering facilities, developing mechanized cargo handling infrastructure to increase throughput, setting up single window facility for cargo clearance, long term contracts with public/ private sector to achieve scale. incentivizing service providers \& users for coastal freight movement

\section{Promote Inland Waterways Transportation (IWT) through}

Coordinated development of infrastructure for first/ last mile transport by construction of riversea vessels to increase carrying capacity, customized vessel financing scheme, incentivizing service providers and users for IWT freight movement, including inland vessels under tonnage tax scheme, removing disparity in GST rates on input/ output activities, modifying customs procedures for transportation of transit goods via IWT.

6. Increased Use of Pipeline Infrastructure By developing model technical guidelines for development of different categories of pipelines, parallel to or under Railway lines, and for Right of Way approvals from different authorities to enhance cost-effective and safe movement of select commodities.

Improving Infrastructure for International Trade by focusing on augmenting physical facilities at 
LCS, upgrading select LCS to ICP, developing infrastructure for off border clearances to reduce border congestion, co-locating inland customs within MMLPs to maximize operational efficiencies, enhancing digitization to expedite clearances, promoting Free Trade Warehousing Zone (FTWZ) to enhance regional/ global trade and develop a Model Process Manual to provide guidance on streamlining and standardization of logistics processes with annual audit to assess logistics efficiency at ports and airports.

\section{Solutions to lack of technical systems}

\section{Fleet management monitoring systems}

(Mauro Vivaldini) explains the objective of the fleet management systems is to provide the company a status and control over its assets by monitoring different variables in their daily operations. These systems enable the company to keep track of information regarding asset utilization, exact location of the material, also the performance of vehicle by track fuel consumption, average speed and much more. The increase in demands from the customers have led the logistics companies to equip devices like mobile communication, Geographical Information Systems (GIS), Global Positioning System (GPS), Automatic Vehicle Location (AVL) etc.

\section{Implementing IoT:}

Internet of Things (IoT) is the system networked connection of mechanical and digital machines or computing devices, physical objects that can enable to collect data or information without human interaction. It brings an interesting innovation change and can transform the logistics business system in India in the accompanying ways:

Predictive analysis and monitoring performance: IoT can be utilized to monitor and store the realtime condition of the assets all over the logistics operations. Many developed countries now being utilizing the advance sensors in their operations to avoid human interactions and also keep track of all the activities in order to terminate slow processes or breakdowns and accidents in the operations.

3. Use of Artificial Intelligence:

Artificial intelligence (AI) can be very useful when it comes to automate business processes and bring down the cost of operations. Activities like quality improvement, elimination of human interaction, and speeding the slow processes can save cost of operations in Logistics. It has found that almost two-third of the total logistics cost are unseen which results in hidden cost and increase logistics cost in India. Hence adoption of AI can automate the ongoing operations and eliminate chances of holding excess inventory, theft, pilferage of cargo and reduce the overall logistics cost. It may also result in reduction of damages to goods by keeping minimum material handling and reduction in time required in inspection by eliminating human interaction.

\section{Blockchain Technology:}

Blockchain is a public, discrete, and distributed archive that removes corporate roughness by being independent of specific applications or contributors. The technology has the potential to alter industries supply chain, including the government, healthcare and more. A practical method to blockchain needs a strong understanding of the business opportunity, the disadvantages, a dependable planning, and a solid execution approach. BiTA (Blockchain in Transport Technology) is an association that is leading the control to support, grow and set standards for blockchain technology within the transportation business.

It can be used to make mutual networks amongst entities unwilling to share data, it brings transparency without compromising on the integrity of the data. This technology turns out to be especially applicable in the Indian context, given the disjointed nature of the sector and absence of mutual platforms to share data. It can be utilized for:

Coordinating multiple logistics value chain: Blockchain technology can be used to bring the processes flawlessly from one point to another by removing the want for duplicity of papers methods. It would also result as a desire to get a combined end-to end logistics system. The goal is to increase communications amongst port clients, with carriers, depots, cargo forwarders, drivers, transporters, among others, by reducing multiple communications among these parties and also avoiding data manipulation.

\section{Cloud Computing}

Cloud computing is a technology which brings widespread, and appropriate contact to a common pool of networks which allows an organization to store data, access to servers and applications that can be retrieved over the web. The logistics industry can be benefited by two ways mentioned below: 
1. Improving Asset utilization: The primary goal of a logistics industry in the country is in the direction of getting leaner, so improving asset consumption can be very vital to boost operational efficiency. The transport sector in India remains extremely uneven \& frequently the vehicle either stays stationary or returns unfilled after transporting the consignment at the destination. This technology can support service providers to use assets more capably by cooperating with each other over the integrated network. Sharing data on cloud-based stages in actual time can aid service providers synchronize and cooperate for the pickup and delivery of load. Improving asset utilization would not only diminish the idle time of the vehicles but would also improve delivery efficiency.

2. Aiding storage and ease to access data: This technology allows the easy capturing of huge sums of data without the necessity for hard drives or servers, LSP's can effortlessly access data from anyplace. This brings flexibility to service providers to flow critical processes smoothly that need day-and-night monitoring from anywhere.

\section{Solution for sustainable development:}

\section{Green Transport:}

Sources which impact the sustainability are the construction of transport network, the operations of transport vehicles, the disposal of transportation vehicles. Practices for removing the negative impact are Modal Choice, Freight Consolidation, Clean Vehicles/Fuel Efficiency, Reuse of Pallets and Containers, Standardization of Trucks Sizes

\section{Green warehousing:}

Sources which impact the sustainability are Layout, design and capacity of the warehouse may impact the sustainability. Practices for removing the negative impact are clean material handling equipment, process optimization, automatic warehousing systems, inventory minimization programs and just-in-time system, Product disposition, on-site recycling

\section{Green packaging:}

Sources which impact the sustainability are the elements of the packaging which have an impact on warehouse and transport costs are size, shape and materials. Practices for removing the negative impact are to sort out the packaging issues, innovative packaging technologies, environmental certifications can be introduced.

\section{Green Procurement:}

Sources which impact the sustainability is lack in quality raw material and the practices for removing the negative impact is quality check monitoring tools

\section{Waste management:}

Sources which impact the sustainability is different kind of waste generate during the logistics like waste from expired product or due to packaging etc. Practices for removing the negative impact are waste contractor, trade waste recycling.

\section{Solution to lack of performance metrics}

The most essential logistics key performance indicators are

\section{Order accuracy}

Keeping tracks of the movement of goods from the placement of the order to the delivery of a shipment. It should be implemented by a logistics service provider which are looking to classify patterns and unceasingly correct faults in order to make transportation safer.

\section{On Time In Full}

This is also known as OTIF, estimates the percentage of orders delivered under the restricted time, without any credentials or document issues. It should be implemented by any LSP's who devoted to providing on time and safe deliveries.

\section{Lead time}

Lead Time is a KPI which indicates the time taken by the LSP's to complete it distribution process from the beginning i.e. picking of product to the delivery of product. It is important to implement strategies to enhance this process time.

\section{Stock rotation}

This KPI is used to calculate the average among the outflows and the remaining balance in the warehouse. This should be implemented by the LSP's who are providing warehousing services with their logistics service.

\section{Truck Turning}

This KPI plays a very important role for those who owns or operate the fleet. It measures the time taken by the vehicle from its time of leaving the destination for pick up as well as delivery and return to its stock location after completing the whole operation.

\section{Capacity utilization}


This KPI measures the utilization of the total capacity by load compared to available capacity during transportation.

\section{Transportation Costs}

It is the measure of all the cost involved in the movement of goods from pick up to delivery. This KPI helps to keep track of the money spent in each operation and reduce unnecessary costs by strategic planning and providing quotations with accurate rate to their clients

\section{Number of shipments}

This KPI measures the average no. of shipments happened in a particular period of time. It can be in weeks, months, quarter or years. This help the LSP's to keep uniform financial balance and analyse their profit margins based on spending's and savings.

\section{CONCLUSION}

The objective of this study is to focus on operational excellence which can benefit to remove inefficiencies in logistics industry and push them on par with global practices. Technology is a key to improve competitiveness and performance by improving the efficiency and total effectiveness of logistics operations. Therefore, implementing the required technology for several logistics activities or sub-processes is crucial to any business with the intention to surge competitive benefit in today's competitive market. The upcoming stage of the LSP's in India focuses ultimately on the value propositions for the clients. These implementations are likely to be very beneficial but will also come at a cost. The future for logistics industry in India is obviously bright and it becomes very important for LSP's in India to deal with all the deficiencies discussed above with the purpose of operating in a costconscious Indian market.

This research can be utilized to understand the complexities in Indian logistics sector and what action should be taken to deal with such problems. It consists of latest reports collected from various resources and include latest government initiatives which would help to make better decisions for logistic services.

\section{REFERENCES}

[1] Andrzej Szymonik $\mathrm{PhD}$ (dr hab. inż.), Lodz University of Technology, the Faculty of Organization and Management, Division of Production Management and Logistics.
[2] Mauro VivaldiniI; Silvio R. I. PiresI; Fernando Bernardi de SouzaII, IMethodist University of Piracicaba - UNIMEP, Brazil IISão Paulo State University Júlio de Mesquita Filho - UNESP, Brazil

[3] Role of Information Technology in Supply Chain Management- Rohita Kumar Mishra.

[4] Tezuka K (2011). 'Rationale for utilizing 3PL in supply chain management: A shippers' economic perspective', IATSS Research, 35, 1, 24-29.

[5] Luthra S, Kumar V, Kumar S, Haleem A (2011), 'Barriers to implement green supply chain management in automobile industry using interpretive structural modeling technique: An Indian perspective', Journal of Industrial Engineering and Management, 4, 2, 231-257.

[6] Christopher, M. (2016). Logistics \& supply chain management. Pearson UK.

[7] Abbasi M, and Nilsson F (2016). "Developing environmentally sustainable logistics: Exploring themes and challenges from a logistics service providers' perspective", Transportation Research Part D: Transport and Environment, 46, 273-283

[8] Anchal Gupta1, Rajesh K.Singh2, P.K.Suri3 Analysis of Challenges faced by Indian Logistics Service Providers

[9] Anil Kumar1 Green Logistics for sustainable development: an analytical review.

[10] Logistics in India: Challenges and Scope S. Ramachandran, Director, AMET B-School, Chennai, India. Mayur S Nakhava, MBA Student, AMET B-School, Chennai, India. Kumar Pratik.

[11] https://lpi.worldbank.org/international/globa 1

[12] https://www.csa.iisc.ac.in/ nv/11India\%20L ogistics\%20Report_Aug2004.pdf

[13] http://www.ijrerd.com/papers/v2-i10/6IJRERD-B527.pdf

[14] https://www.jll.co.in/content/dam/jll com/documents/pdf/research/apac/india/jll- 
latest-report-india-evolution-of-integratedlogistics.pdf

[15] https://www.logisticsmgmt.com/article/top 8_logistics_challenges_facing_the_industry

[16] https://www.scielo.br/scielo.php?script=sci_ arttext\&pid=S1807-17752012000300006

[17] https://www2.deloitte.com/content/dam/Del oitte/in/Documents/public-sector/in-psindia-on-cusp-of-a-logistics-revolutionnoexp.pdf

[18] https://pib.gov.in/PressReleaseIframePage.a spx?PRID $=1540616$

[19] https://commerce.gov.in/writereaddata/Uplo adedFile/MOC_636850457336854610_Noti fication-Draft-05022019.pdf 